\title{
Análise de uma Sequência Didática Investigativa SOBRE ESTEQUIOMETRIA ABORDANDO A QUÍMICA DOS SABÕES E DETERGENTES
}

\author{
ANALYSIS OF AN INVESTIGATIVE TEACHING SEQUENCE ABOUT \\ STOICHIOMETRY RELATED TO THE CHEMISTRY OF SOAPS AND \\ DETERGENTS
}

DOI: $10.23926 / R P D .2526-2149.2020 . v 5 . n 2 . p 1256-1277 . i d 736$

\section{Aline Aparecida \\ Teixeira da Silva \\ Mestre em Química (UFV) \\ Professora no Colégio \\ Coeducar - Viçosa (MG) \\ alineapteixeiras@yahoo.com \\ .br}

\section{Vinícius Catão \\ Doutor em Educação \\ (UFMG) \\ Professor na Universidade \\ Federal de Viçosa (UFV) \\ vcasouza@ufv.br}

\section{Aparecida de Fátima Andrade da Silva \\ Doutora em Ensino de Ciências (USP) \\ Professora na Universidade Federal de Viçosa (UFV.) aparecida.silva@ufv.br}

Resumo: O presente trabalho descreve e analisa uma Sequência Didática Investigativa que abordou a Química dos sabões e detergentes. Ela foi elaborada para ensinar Estequiometria de forma contextualizada aos estudantes da $2^{\text {a }}$ Série do Ensino Médio, em uma escola privada na cidade de Viçosa (MG), sendo discutida ao longo de oito aulas de cinquenta minutos. Para analisar os dados, foram feitos Estudos de Casos com a descrição das aulas, tendo como base as transcrições dos áudios, as respostas dos estudantes às atividades, além das notas de campo. Essa análise nos permitiu concluir que o modo como foi abordado o conteúdo de Estequiometria em sala de aula, por meio de atividades experimentais investigativas e com abordagens contextuais, favoreceu debates sobre questões sociocientíficas que permitiram problematizar o conteúdo, proporcionando aos estudantes um processo formativo mais dinâmico e participativo. Isso favoreceu uma melhor compreensão do conteúdo químico, bem como a formação cidadã.

Palavras-chave: Cálculos Estequiométricos; Transformações Químicas; Contextualização.

\begin{abstract}
This paper describes and analyzes an Investigative Teaching Sequence (ITS) that approached the Chemistry of soaps and detergents. The ITS was designed to teach Stoichiometry in a contextual way to a class from the 2nd Grade of High School (15-16 years old) of a High School in the Viçosa's town (Brazil), being discussed over eight classes of fifty minutes. To proceed the data analysis, eight Case Studies were prepared with description of the classes, based on the audios' transcripts, students' answers and field notes. This analysis allowed conclude that the Stoichiometry discussed in the classroom through experimental investigative activities and with contextual approaches favored debates on socioscientific issues. Its form of teaching approach allowed problematize the discussion, providing students with a more dynamic and participative interaction on the classes. This instructional process was led the students to a better understanding of the chemical content, as well as critical citizen formation.
\end{abstract}

Keywords: Stoichiometric Studies; Chemical Transformations; Contextualization. 


\section{INTRODUÇÃO: CONTEXTO DO TRABALHO E REFERENCIAIS TEÓRICOS}

Trabalhos na área da Educação em Ciências apontam que vários estudantes apresentam expressivas dificuldades para compreender conceitos científicos e, muitas vezes, o desempenho insatisfatório está associado ao modo como o conteúdo foi ensinado (GARCIA; KRUGER, 2009; POZO; CRESPO, 2009; COSTA; SOUZA, 2013). Tais dificuldades podem se relacionar aos três níveis de compreensão da matéria, entendidos por Johnstone (1993) como sendo o: (i) macroscópico (descritivo), no qual é possível ver e manipular materiais distintos por meio dos sentidos; (ii) representacional (simbólico), no qual se utilizam fórmulas e equações químicas para mostrar as transformações da matéria; e (iii) submicroscópico (explicativo), relativo ao mundo (sub)micro dos átomos, moléculas, íons e demais espécies químicas.

A Ciência ensinada nas escolas, na perspectiva de um ensino tradicional e amplamente conteudista, demonstra não ter relação direta com a Química da vida, tão presente no dia a dia dos estudantes, bem como com os seus usos e aplicações na sociedade. O que se verifica atualmente é a predominância de um ensino de Ciências descontextualizado e muitas vezes destituído de sentido, sem relações efetivas com as questões sociais, ambientais e tecnológicas. O estudante é levado a aceitar, de forma passiva e pouco refletida, aquilo que o professor apresenta, sem espaço para argumentar, expressar suas ideias e questionar o motivo pelo qual está aprendendo determinado conteúdo. No sentido contrário a essa abordagem, que demonstra pouca efetividade para a aprendizagem, pesquisas no campo do ensino de Ciências destacam a importância de se articular um ensino contextual e investigativo, que permita a problematização do objeto de estudo e favoreça condições para que o mesmo seja investigado pelos alunos (ZÔMPERO; LABURÚ, 2011; CARVALHO, 2011; CARVALHO, 2013; SASSERON, 2015; SEDANO; CARVALHO, 2017; CARVALHO; 2018; SANTANA; CAPECCHI; FRANZOLIN, 2018). Assim, Carvalho (2011) aponta para a necessidade de um ensino de Ciências que seja planejado e autêntico, de modo a:

[...] ir além do trabalho com conceitos e ideias científicas: é preciso que a escola ofereça condições para que a cultura da Ciência seja conhecida pelos estudantes. É necessário introduzir os alunos no universo das Ciências, isto é, ensinar os alunos a construir conhecimento fazendo com que eles, ao perceberem os fenômenos da natureza, sejam capazes de construir suas próprias hipóteses, elaborar suas próprias ideias, organizando-as e buscando explicações para os fenômenos. Ao ensinarmos Ciências por investigação estamos proporcionando aos alunos oportunidades para olharem os problemas do mundo elaborando estratégias e planos de ação. Desta forma, o ensino de Ciências se propõe a preparar o aluno desenvolvendo, na sala de aula, habilidades que lhes permitam atuar consciente e racionalmente fora do contexto escolar. (CARVALHO, 2011, p. 253). 
Nesse sentido, é importante que o ensino de Ciências proporcione condições aos alunos para construírem novos conhecimentos, bem como o desenvolvimento de habilidades cognitivas, além de atitudes e valores inerentes à formação de cidadãos críticos, conscientes e responsáveis para atuarem como agentes transformadores do seu meio. Entretanto, o ensino de Ciências instituído em muitas escolas ainda se pauta pela relação de transmissão-recepção de informações descontextualizadas. Entendemos que dessa maneira a efetividade da educação científica pode ser comprometida, sobretudo por desconsiderar a importância das práticas investigativas e da sua relação com o desenvolvimento cognitivo dos alunos ao longo do processo de aprendizagem (POZO; CRESPO, 2009). Concordamos com Carvalho (2011) quando a autora discute alguns dos aspectos relativos ao processo de ensino investigativo em sala de aula, abordando a necessidade de o professor considerar: (i) a importância de um problema para se iniciar a construção de novos conhecimentos; (ii) o entendimento da ação manipulativa e interativa para a ação intelectual; (iii) a importância da tomada de consciência dos atos para a construção de novos conhecimentos; e (iv) as diferentes etapas relacionadas às explicações científicas, que muitas vezes passa da observação inicial de um fenômeno para o seu posterior entendimento, quando os estudantes buscam uma explicação com base nas experiências prévias ou naquelas compartilhadas entre os pares.

Santos e Schnetzler (2010) apontam ainda para a necessidade de um ensino de Química contextualizado e em diálogo com a vida dos estudantes. Para tal, acredita-se que fazer Ciências por meio de atividades dialógicas, investigativas e relacionadas ao dia a dia pode favorecer um maior engajamento com o processo educativo, desenvolvendo habilidades essenciais para a formação de cidadãos atuantes frente as questões sociais, ambientais, éticas, políticas e tecnológicas que perpassam a sociedade como um todo. Santos e Schnetzler (2010) consideram ainda que, no currículo de Química voltado à formação cidadã, é importante abordar o conteúdo de Cálculos Estequiométricos, pois ele contempla os três níveis para compreensão da matéria aqui apresentados, com base em Johnstone (1993). Para Santos e Silva (2014, p. 134), o estudo da Estequiometria aborda “[...] as relações quantitativas das transformações químicas que estão implícitas nas fórmulas e nas equações químicas. Estas últimas são expressões simbólicas para as relações quantitativas a nível macroscópico e submicroscópico". Entretanto, a inter-relação estabelecida entre esses três níveis tem sido um grande desafio para muitos professores e estudantes. Isso pode comprometer o ensino e a aprendizagem deste conteúdo considerado central para a compreensão dos processos químicos, como apontado nos trabalhos de Lourenço e Marcondes (2003), Pio (2006), Costa e Souza (2013), Santos (2013) e Silva (2015). 
Diante disso, foi elaborada e discutida em sala de aula uma Sequência Didática Investigativa (SDI) relacionada ao conteúdo de Cálculos Estequiométricos, a partir de uma abordagem contextual relacionada aos aspectos químicos dos sabões e detergentes. De acordo com Leal e Fonseca (2013), uma Sequência Didática se refere ao conjunto de atividades planejadas pelo docente, etapa por etapa, abordando estratégias de ensino diversificadas. A Sequência Didática representa uma possibilidade de ação pedagógica sobre um conteúdo específico que, ao ser discutido em sala de aula, possibilita ao discente uma melhor compreensão dos assuntos considerados mais difíceis, como a Estequiometria.

A Sequência Didática proposta neste trabalho buscou desenvolver uma metodologia diferenciada daquela presente na maioria dos livros didáticos, que normalmente prioriza o estudo mecânico da Estequiometria, a partir de situações nas quais os alunos resolvem os exercícios seguindo as etapas apresentadas pelo docente ou pelo livro utilizado. Assim, na SDI a construção do conhecimento foi mediada pela professora, que buscou sempre favorecer a efetiva participação dos alunos nas atividades, com vista à compreensão dos conteúdos químicos, além do desenvolvimento de habilidades atitudinais por meio das questões sociocientíficas abordadas. Nesse sentido, buscando proporcionar aos alunos um ensino mais autêntico, dinâmico e participativo, ao longo da SDI foram propostas atividades experimentais investigativas, questões sociocientíficas e algumas discussões que permitiram problematizar o conteúdo. Com isso, a professora conseguiu envolver a maioria dos estudantes nas discussões fomentadas em sala de aula, por meio da "[...] contextualização dos temas sociais, na qual se solicita a opinião dos alunos a respeito do problema que o tema apresenta, antes mesmo de ser discutido do ponto de vista da Química” (SANTOS; SCHNETZLER, 2010, p. 120).

Adita-se a isso a importância do uso de experimentos em contextos investigativos. De acordo com Guimarães (2009), as atividades experimentais são necessárias para favorecer um ensino de Química contextualizado, pois ao incluir práticas que desafiam os estudantes com situações-problemas concretas, o professor contribui para que estas favoreçam a construção de novos conhecimentos, além da negociação de sentidos pela argumentação e interlocução entre realidade e prática. Nesse sentido, Carvalho (2018) discutiu que a experimentação, ao apresentar um caráter investigativo, pode contribuir para instigar a curiosidade e o interesse dos educandos em aprender Ciências. Os alunos ao serem motivados a resolverem uma situaçãoproblema, são encorajados a formularem hipóteses, testá-las de diferentes maneiras e modificálas de acordo com os resultados. Sobre este aspecto e, em diálogo com a Base Nacional Comum Curricular para o Ensino Médio - BNCC (BRASIL, 2018), essa natureza investigativa do 
processo de ensino e aprendizagem inquieta os alunos e os motiva a construírem novos conhecimentos, ao invés de simplesmente memorizá-los passivamente, em uma relação de transmissão-recepção que normalmente acontece sem um viés crítico e reflexivo sobre o que se aprende. A BNCC é um documento que se fundamenta na busca pela aprendizagem igualitária, bem como no desenvolvimento de competências consideradas essenciais para a formação de sujeitos autônomos, capazes de aplicar os conhecimentos adquiridos na escola em sua vida cotidiana (BRASIL, 2018). Nesse sentido, entende-se ser fundamental que na Sequência Didática esteja presente, além de experimentos com natureza investigativa, questões sociocientíficas que possam problematizar o processo formativo, assim como estimular o desenvolvimento da discussão e da argumentação pelos alunos, mediado pelo professor em sala de aula.

De acordo com Latini et al. (2013), é importante que o ensino de Química seja capaz de desenvolver nos estudantes o interesse pelos assuntos sociais vinculados a esta Ciência. Para conseguir isso, se faz necessário um ensino mais dialógico e comprometido com a problemática socioambiental, pois dessa forma "favorece o estabelecimento de relações com a realidade dos estudantes, possibilitando uma melhor assimilação do conhecimento construído em sala de aula" (LATINI et al., 2013, p. 12). Além disso, um ensino de Química com abordagem CTS (Ciência, Tecnologia e Sociedade) contribui para aumentar o interesse por questões contextuais relacionadas à disciplina, o que possibilita aos estudantes participarem de debates e assumirem "uma postura comprometida em buscar posicionamentos sobre o enfrentamento dos problemas ambientais e sociais vinculados às aplicações da Química na sociedade" (SANTOS; SCHNETZLER, 2010, p. 303). A importância desse debate dialoga com a reflexão trazida por Paulo Freire sobre a essência do processo educativo, quando ele nos advertiu que

[...] a existência, porque humana, não pode ser muda, silenciosa, nem tampouco pode nutrir-se de falsas palavras, mas de palavras verdadeiras, com que os homens transformam o mundo. Existir, humanamente, é pronunciar o mundo, é modificá-lo. O mundo pronunciado, por sua vez, se volta problematizado aos sujeitos pronunciantes, a exigir deles novo pronunciar. Não é no silêncio que os homens se fazem, mas na palavra, no trabalho, na ação-reflexão. (FREIRE, 1987, p. 78).

Acreditamos que ao articular temas contextuais relacionados à Ciência, Tecnologia e Sociedade, o professor poderá fomentar discussões que envolvam os estudantes e despertem neles o interesse pela Ciência, bem como a consciência para assumir atitudes mais responsáveis e sustentáveis. Nesse sentido, Ferraz e Sasseron (2017) discutem a importância de o professor criar situações que oportunizam o debate em sala de aula, permitindo a participação ativa dos alunos e os aproximando das práticas relacionadas à cultura científica. Além disso, os autores 
defendem que esse é um momento importante para o compartilhamento de diferentes pontos de vistas, o que permite o desenvolvimento de habilidades cognitivas, as quais "além de favorecer compreensões sobre conteúdos científicos, podem ser extrapoladas e generalizadas para situações cotidianas" (FERRAZ; SASSERON, 2017, p. 6).

Diante disso, a discussão sobre questões sociocientíficas em sala de aula estimularia habilidades relacionadas à capacidade de tomada de decisão que, de acordo com Santos e Maldaner (2011) e Ferraz e Sasseron (2017), decorre da necessidade de se desenvolver posturas críticas de julgamento e de criar justificativas para sustentar um determinado ponto de vista. Nesse sentido, entende-se que "são as justificativas que conferem força e validade a um argumento, podendo ser incorporadas por meio de ações orais ou produções escritas, por pessoas situadas em diferentes contextos que articulam diferentes evidências de natureza conceitual ou empírica" (FERRAZ; SASSERON, 2017, p. 7). Assim, compreende-se que um ensino de Química pleno de sentido precisa assegurar o engajamento e a participação de todos, fomentando debates em sala de aula e propondo a discussão de questões em que os alunos tenham a oportunidade de propor soluções para problemas da vida real.

Mediante este contexto, delineou-se a escolha do tema investigado relacionado à sabões e detergentes, apontando para a necessidade de se desenvolver uma proposta de ensino contextualizada, por meio de uma SDI que contribuísse para que estudantes e professores pudessem superar eventuais obstáculos encontrados no processo de ensino e aprendizagem da Estequiometria. Dessa forma, o cerne desta pesquisa foi verificar a efetividade da SDI aqui proposta, investigando se os alunos tiveram uma melhor compreensão dos conteúdos abordados após a aplicação das atividades e se elas favoreceram atitudes mais conscientes por meio das questões socioambientais articuladas no material formativo.

\section{ASPECTOS METODOLÓGICOS}

A pesquisa aqui descrita é de natureza qualitativa, em que o ambiente da Escola foi o espaço para a coleta dos dados e a professora-pesquisadora se mostrou fundamental nesse processo, mediando as relações de conhecimento estabelecidas em sala de aula. Buscou-se analisar ações individuais e as interações estabelecidas a partir de uma investigação acerca dos conceitos químicos sobre Estequiometria abordados na SDI. Este estudo foi classificado como Pesquisa Participante, pois houve o envolvimento ativo tanto da pesquisadora (professora regente da turma), quanto do grupo pesquisado (alunos). Méksenas (2007) aponta que em uma Pesquisa Participante tanto o pesquisador quanto os sujeitos pesquisados contribuem para o 
processo de construção do conhecimento no espaço da pesquisa. Assim, o trabalho foi desenvolvido em uma escola particular na cidade de Viçosa (MG). Participaram da pesquisa 24 alunos da $2^{\text {a }}$ Série do Ensino Médio que já haviam estudado o conteúdo de Estequiometria no final da $1^{\text {a }}$ Série. Naquela ocasião, a abordagem do assunto ocorreu de maneira tradicional, com aulas expositivas, realização de experimentos demonstrativos e discussões que buscavam aplicar o conhecimento estudado na resolução de alguns exercícios propostos pelo livro didático. É importante destacar o motivo pelo qual escolheu-se para participar da pesquisa o mesmo grupo de alunos que já havia estudado Estequiometria na Série anterior. Como eles tiveram contato com o conteúdo de Cálculos Estequiométricos por meio de uma abordagem de ensino tradicional, pautada na relação de transmissão-recepção, após a discussão da SDI seria possível fazermos uma comparação sobre as diferentes metodologias.

A SDI foi discutida em oito aulas com duração de cinquenta minutos cada, sendo todas elas gravadas para a posterior transcrição dos áudios, que constituíram uma das fontes de dados desta pesquisa. Para avaliar o processo formativo, investigando se os alunos tiveram uma melhor compreensão dos conteúdos abordados após a discussão da SDI, foram feitos Estudos de Caso com vistas a compreender em profundidade o fenômeno estudado. Assim, decidiu-se elaborar um Estudo de Caso para cada aula da SDI. Eles foram feitos utilizando como fontes de dados a descrição trazida nos áudios das aulas transcritas, as respostas dos estudantes às questões presentes no material escrito produzido, além das impressões e anotações da professora-pesquisadora ao longo do processo de ensino (notas de campo), visando sempre obtermos dados fidedignos para responder à questão de pesquisa.

Nos Estudos de Caso, todos os sujeitos da pesquisa foram representados por códigos alfa numéricos, sendo a professora-pesquisadora identificada pelo código $\mathrm{P}$ e cada aluno por um código do tipo $\mathrm{Ax}$, em que $\mathrm{x}$ representou um número de ordem atribuído aleatoriamente. Isso garantiu o anonimato e assegurou que nenhum constrangimento seria gerado aos participantes, conforme disposto na Resolução 466 do Conselho Nacional de Saúde - CNS, de 12/12/2012. Além disso, todas as falas da professora-pesquisadora e dos alunos foram marcadas em itálico para que, dessa forma, fossem distinguidas das demais ideias apresentadas no decorrer do texto. De acordo com Godoy (1995), o Estudo de Caso é um importante recurso para analisar o conteúdo de observações que foram coletadas no ambiente de pesquisa. Para esta análise, foi feita a descrição de todas as aulas da SDI, trazendo detalhes das atividades realizadas a partir dos áudios e das observações feitas nas aulas. Segundo Yin (2005), os registros das observações das aulas, bem como a descrição das mesmas, constituem as notas de 
campo. Elas representam uma importante fonte de dados quando tais anotações são planejadas previamente, de modo a delimitar o que será anotado e observado, garantindo assim o foco da investigação e o não desvio da proposta inicial da pesquisa.

O Quadro 1 a seguir apresenta uma breve descrição das aulas ministradas durante a aplicação da SDI. Essa descrição sucinta tem como finalidade apresentar ao leitor uma visão geral sobre o que foi feito em sala de aula e o que será analisado a seguir.

Quadro 1 - Breve descrição das aulas em que a SDI foi discutida

\begin{tabular}{|c|c|c|}
\hline $\begin{array}{l}\text { Ordem } \\
\text { das } \\
\text { aulas }\end{array}$ & $\begin{array}{l}\text { Temáticas das } \\
\text { aulas }\end{array}$ & Breve descrição das aulas \\
\hline $1^{\mathrm{a}}$ & $\begin{array}{l}\text { Tensão superficial } \\
\text { da água e sua } \\
\text { importância para } \\
\text { o meio ambiente }\end{array}$ & $\begin{array}{l}\text { A professora apresentou as seguintes questões para problematizar: O que é } \\
\text { feito com os óleos e gorduras após utilizá-los em casa? Qual a diferença } \\
\text { entre sabão e detergente? Qual deles polui mais o meio ambiente? O que é } \\
\text { sabão ou detergente biodegradável? Você sabe a diferença entre o amaciante } \\
\text { comum e o amaciante concentrado? O que é a tensão superficial da água? } \\
\text { Em seguida, discutiu a tensão superficial da água e sua importância para o } \\
\text { meio ambiente. Para verificar a influência dos detergentes na tensão } \\
\text { superficial da água, os alunos fizeram um experimento utilizando água, raspas } \\
\text { de giz, conta-gotas e detergente. Após a realização do experimento, eles } \\
\text { registraram em grupo as observações dos resultados desta atividade. }\end{array}$ \\
\hline $2^{a}$ & $\begin{array}{l}\text { Vamos refletir... } \\
\text { Detergente ou } \\
\text { sabão: qual polui } \\
\text { mais? }\end{array}$ & $\begin{array}{l}\text { A partir da leitura e discussão do texto “Detergente ou sabão: qual polui } \\
\text { mais?", os alunos puderam conhecer a estrutura química do sabão, do } \\
\text { detergente biodegradável e do não biodegradável. Em seguida, responderam } \\
\text { em grupo às questões referentes ao texto. }\end{array}$ \\
\hline $3^{\mathrm{a}}$ & $\begin{array}{l}\text { A Química em } \\
\text { nossas vidas... } \\
\text { Conhecendo sobre } \\
\text { a Química dos } \\
\text { sabões e } \\
\text { detergentes } \\
\end{array}$ & $\begin{array}{l}\text { A professora utilizou uma apresentação multimídia intitulada: A Química dos } \\
\text { sabões e detergentes. Durante a discussão, os alunos foram instigados a } \\
\text { responderem perguntas feitas pela professora, expressando o conhecimento } \\
\text { que tinham em relação à polaridade das moléculas e a solubilidade. Para } \\
\text { finalizar a aula, eles construíram um modelo que representava a estrutura } \\
\text { química de uma micela. }\end{array}$ \\
\hline $4^{\mathrm{a}}$ & $\begin{array}{l}\text { Realização de } \\
\text { testes em } \\
\text { amostras de } \\
\text { detergentes }\end{array}$ & $\begin{array}{l}\text { Realizaram-se dois testes. O primeiro comparou visualmente a concentração } \\
\text { de quatro detergentes de marcas distintas. No segundo, foi comparada a } \\
\text { viscosidade do detergente e do amaciante comum, cronometrando o tempo em } \\
\text { que uma pequena esfera de aço gastava para percorrer a mesma profundidade } \\
\text { de líquidos diferentes. Em seguida, fez-se a discussão do texto "O que } \\
\text { podemos aprender com os experimentos feitos em sala", abordando conceitos } \\
\text { de viscosidade e concentração, além das vantagens de utilizar o amaciante } \\
\text { concentrado em relação ao comum, principalmente em termos ambientais. }\end{array}$ \\
\hline $5^{\mathrm{a}}$ & $\begin{array}{l}\text { Colocando a mão } \\
\text { na massa: } \\
\text { produção de } \\
\text { sabão ecológico }\end{array}$ & $\begin{array}{l}\text { Os alunos foram para o Laboratório e, em grupo, resolveram as três primeiras } \\
\text { questões da SDI. Em seguida, produziram o sabão ecológico, verificando } \\
\text { como o óleo de cozinha pode ser reutilizado para a fabricação de sabão. }\end{array}$ \\
\hline $6^{\mathrm{a}}$ & $\begin{array}{l}\text { Estequiometria: a } \\
\text { matemática da } \\
\text { Química }\end{array}$ & $\begin{array}{l}\text { O conceito de Estequiometria foi abordado por meio da pergunta: Para } \\
\text { fabricar o sabão ecológico foi necessário dissolver certa quantidade de soda } \\
\text { cáustica }[\mathrm{NaOH}] \text { em água. Em seguida, foi misturado óleo filtrado a essa } \\
\text { solução. Caso seja necessário triplicar essa receita, qual a quantidade de } \\
\text { soda cáustica, água e óleo precisaremos utilizar? A partir da discussão } \\
\text { inicial, a professora apresentou algumas estratégias que poderiam auxiliar na } \\
\text { resolução de questões que abordam esse tema. Em seguida, foi feita uma } \\
\text { atividade para mostrar o rearranjo de átomos em uma reação e a importância } \\
\text { do balanceamento da equação química. }\end{array}$ \\
\hline
\end{tabular}




\begin{tabular}{|c|c|c|}
\hline $7^{\mathrm{a}}$ & $\begin{array}{c}\text { Aplicando o } \\
\text { conhecimento } \\
\text { científico }\end{array}$ & Os alunos foram para o Laboratório e, em grupo, resolveram as questões \\
propostas na SDI.
\end{tabular}

Fonte: Autores.

\section{Resultados E discuSSÃo}

A seguir será apresentado os Estudos de Caso contendo a descrição analítica do processo de ensino que ocorreu em cada aula da SDI. É importante ressaltar que na primeira aula a professora organizou os estudantes em cinco grupos. Os grupos, em diversos momentos ao longo da SDI, se reuniram no Laboratório para discutir e responder as questões propostas.

Estudo de caso referente a primeira aula da SDI: Inicialmente, foram levantadas as ideias prévias dos estudantes sobre as seguintes questões sociocientíficas: $O$ que é feito com os óleos e as gorduras após utilizá-los em casa? Qual a diferença entre sabão e detergente? Qual deles polui mais o meio ambiente? O que é sabão ou detergente biodegradável? Você sabe a diferença entre o amaciante comum e o amaciante concentrado? O que é a tensão superficial da água? As perguntas fomentaram a discussão junto aos alunos, favorecendo a argumentação durante a aula. Isso pode ser verificado na passagem a seguir, em que dois estudantes (A5 e A9) apresentaram ideias distintas sobre a diferença entre sabão e detergente:

P: Vocês sabem qual a diferença entre sabão e detergente? A3: Eu acho que na fórmula do detergente tem uma parte polar e uma apolar. A4: Eu acho que o detergente é desengordurante. A5: O detergente é melhor para lavar louça, resposta que fez A9 discordar, argumentando que considera o sabão melhor.

A pergunta feita pela professora no momento seguinte a essa passagem evidenciou que a discussão sobre questões sociocientíficas em sala de aula pode estimular habilidades relacionadas à capacidade de tomada de decisão que, de acordo com Santos e Maldaner (2011) e Ferraz e Sasseron (2017), decorre da necessidade de se desenvolver posturas críticas de julgamento e de criar justificativas para sustentar um determinado ponto de vista, fato que pode ser verificado nos turnos de fala transcritos a seguir:

P: O que é sabão ou detergente biodegradável? Qual a importância deles para o ambiente? A23: Ele se decompõe, se degrada. P: Mas ele se degrada pela ação de quem? A23: Pela vida, bio é vida. 
A partir dos turnos apresentados anteriormente, constatamos que A23 demonstrou não conhecer o processo de degradação do detergente no ambiente, mas expressou o entendimento baseado na palavra Biodegradável e na sua possível relação com o processo químico. Nesse momento, coube à professora prosseguir com a construção conceitual, permitindo aos alunos um entendimento além do processo, em diálogo com as questões da Ciência. À medida que as discussões ocorreram, a professora procurou verificar os conhecimentos dos alunos sobre o tema ambiental relacionado ao uso dos sabões e detergentes, bem como acerca dos conteúdos científicos abordados na SDI. Assim, os questionamentos feitos foram responsáveis por uma ampla discussão, conforme se destaca no trecho transcrito a seguir:

P: Vocês sabem a diferença entre o amaciante comum e o amaciante concentrado? A24 [responde rapidamente]: Eu sei que o concentrado é mais cheiroso, mais forte. A4: Tem menos água e mais soluto. P: Vocês sabem o que é a tensão superficial da água? A9: É uma película que se forma e permiti os insetinhos andarem sobre a superfície da água. P: Mas o que é essa película? A5: São as ligações de hidrogênio formadas entre as moléculas de água. [A4, A5 e A9 lembraram que no ano anterior foram feitos experimentos quando estudaram a tensão superficial].

Essa discussão permitiu constatar importantes relações entre as ideias dos alunos relativas ao senso comum e a Ciência: o amaciante concentrado é mais cheiroso e mais forte porque tem mais soluto. Ao mesmo tempo, possibilitou resgatar conceitos trabalhados na Série anterior, como as interações químicas do tipo Ligação de Hidrogênio. Além disso, diferente do que ocorreu nas aulas tradicionais, a inserção das questões sociocientíficas no contexto escolar favoreceu o debate em sala de aula e propiciou um maior envolvimento dos alunos na discussão. Isso, de acordo com Ferraz e Sasseron (2017), é considerado um momento ideal e propício ao compartilhamento de diferentes pontos de vistas, permitindo o desenvolvimento de habilidades cognitivas, as quais "além de favorecer compreensões sobre conteúdos científicos, podem ser extrapoladas e generalizadas para situações cotidianas" (FERRAZ; SASSERON, 2017, p. 6). Após a discussão inicial, a professora pediu para os alunos irem ao Laboratório e, em grupo, verificar a influência dos detergentes na tensão superficial da água por meio de um experimento simples. Na execução do mesmo, os alunos se mostraram entusiasmados e, por já terem estudado a tensão superficial na Série anterior, fizeram a descrição das observações experimentais sem qualquer dificuldade. 
Estudo de caso referente a segunda aula da SDI: Iniciou-se a aula com a leitura e discussão do texto Detergente ou sabão: qual polui mais? Após a leitura, a professora apresentou as estruturas químicas do sabão, do detergente biodegradável e do detergente não biodegradável. Naquele momento, os alunos foram introduzidos às estruturas químicas de alguns compostos orgânicos, a serem estudados mais profundamente por eles na $3^{\mathrm{a}}$ série do Ensino Médio. Quando foram solicitados a responder o que significava o detergente ser biodegradável, A5 rapidamente associou este termo a uma conhecida marca comercial, que utiliza como marketing o fato de fabricar produtos biodegradáveis. A professora aproveitou para explicar que os produtos biodegradáveis se decompõem na presença de microrganismos vivos, sendo transformados em moléculas neutras (água e gás carbônico) e em íons (nitritos, nitratos, fosfatos, sulfatos). Ressaltou ainda que tais produtos podem ser utilizados como nutrientes para as plantas. Essa discussão evidenciou um ensino dialógico e comprometido com questões socioambientais a partir do estabelecimento de relações com a realidade dos estudantes. Além disso, permitiu a eles analisarem e avaliarem situações do cotidiano a partir do conhecimento químico adquirido em sala de aula (LATINI et al., 2013; SASSERON, 2015). Na discussão final sobre o texto, A4 e A10 fizeram comentários que, assim como ocorreu no início da aula, ressaltaram a importância de abordar temas que integram Ciência, Tecnologia e Sociedade em sala de aula e favoreceu o desenvolvimento de "uma postura comprometida em buscar posicionamentos sobre o enfrentamento dos problemas ambientais e sociais vinculados às aplicações da Química na sociedade" (SANTOS; MALDANER 2011, p. 303). A4 e A10 apontaram que os detergentes ou os sabões descartados diretamente no meio ambiente vão causar grandes impactos. De acordo com eles, todos os esgotos domésticos e industriais deveriam ser tratados antes de serem descartados nos rios e mares.

Estudo de caso referente a terceira aula da SDI: Esta aula foi ministrada usando como recurso didático uma apresentação multimídia intitulada A Química dos sabões e detergentes. A professora iniciou com a pergunta vocês já lavaram prato engordurado somente com água? Esse questionamento fomentou uma ampla discussão sobre polaridade das moléculas e solubilidade, conforme destacamos no trecho transcrito a seguir:

P: Vocês já lavaram prato engordurado somente com água? A17: Já! não limpa, não! Em seguida, a professora questionou: Com qual aspecto vai ficar? A3: Fica engordurado. A24: Ensebado. A9: Não mistura a água com a gordura. P: Moléculas de água são polares e de gorduras são apolares. Por isso não se misturam, não existe afinidade química entre elas! 
Na sequência, foi apresentada mais uma pergunta pela professora: $O$ que poderia ajudar a retirar a gordura dos pratos? A3, A5, A9 e A23 responderam: Sabão e detergente. Logo em seguida, a professora questionou: Mas vocês já tentaram remover a gordura de uma panela usando somente sabão ou detergente? A23 disse: Já tentei... não dá certo, também! Então, a turma concluiu que para remover a gordura seria necessário usar sabão ou detergente e, também, água. A partir dessa discussão, foi possível verificar que os alunos sabiam previamente que a água e a gordura não se misturam, uma vez que são moléculas com polaridades diferentes, em que a água é polar e a gordura apolar. A partir dos conhecimentos prévios e experienciais, eles foram capazes de responder que para retirar a gordura dos pratos seria necessário usar sabão ou detergente. Como demonstrado anteriormente, a professora tentou contribuir para enriquecer ainda mais a discussão dizendo aos alunos que o sabão ou o detergente sozinho não remove a gordura e que, além deles, é fundamental também a presença da água. Na sequência, A3, A5 e A24 fizeram uma importante observação sobre a ação do detergente ou do sabão no processo de limpeza e o diálogo prosseguiu:

A3, A5 e A24: $O$ detergente se junta à molécula de gordura e à molécula de água e sai... A professora disse: Sai para onde? Mas quem vai ajudar ele sair? A5 respondeu: A água. Então é assim: Quando o sabão reage com a gordura é como se fosse assim: a água vem pegando uma molécula de detergente que está junto com a gordura e vai saindo igual uma quadrilha... vem o par e vai pegando a menina e indo. A3 completou: $O$ detergente necessita ter uma parte polar e outra apolar, de maneira a interagir tanto com a água quanto com a gordura. A professora perguntou: A parte polar do detergente vai interagir com quem? A8 disse: Vai interagir com a água. Em seguida, ao perguntar com quem a parte apolar iria interagir, os alunos foram unânimes em responder que seria com a gordura.

Essa discussão demonstrou uma interessante associação estabelecida por A5, correlacionando a ação do detergente no processo de remoção da gordura com uma quadrilha (das Festas Juninas). Isso levou A3 concluir com ênfase que o detergente tem uma parte polar e outra apolar, o que possibilita interagir tanto com a água, quanto com a gordura. A partir desse momento, a professora iniciou a explicação acerca de como o sabão e o detergente atuam na limpeza, discutindo que ao adicionar sabão ou detergente na água, suas moléculas se distribuem na forma de "pequenos glóbulos" chamados micelas. Para exemplificar o processo de formação das micelas e a sua importância no processo de remoção da gordura, a professora propôs à turma construir um modelo que representasse a estrutura da micela. Para isso, colou um papel cartão 
azul no quadro e fixou, no seu centro, um papel amarelo que representava a partícula de gordura. Em seguida, mostrou o modelo de uma estrutura que representava o detergente e a outra que representava a água. Posteriormente, informou aos estudantes que a micela teria uma forma globular e destacou que a parte branca da estrutura representando o detergente seria apolar. Em seguida, solicitou a participação dos alunos na construção da micela. A1 iniciou colocando a parte apolar do detergente voltada para a molécula de gordura e a parte polar mais afastada da gordura. Isso motivou a participação dos demais na atividade proposta, resultando na montagem do modelo apresentado na Figura 1.

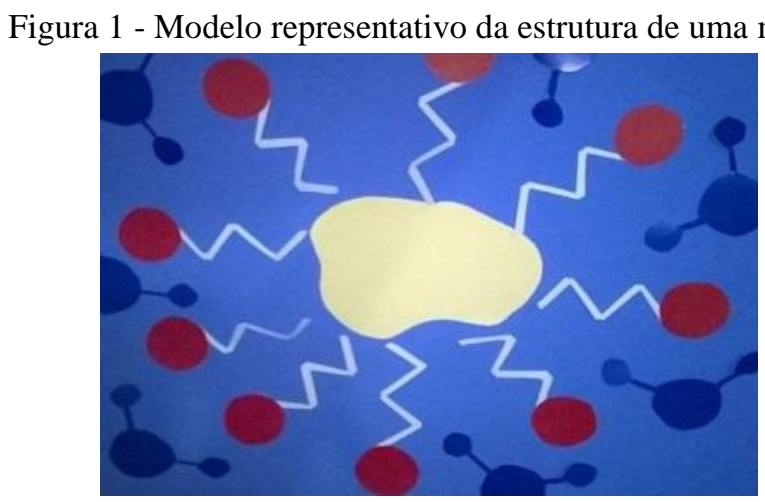

Fonte: Autores.

A dinâmica permitiu uma maior participação e envolvimento dos alunos na aula. Após concluir a micela, a professora ressaltou que a capacidade de limpeza do sabão ou detergente não depende da sua espuma, mas da propriedade de formar micelas estáveis. A explicação parece ter sido esclarecedora, como podemos verificar na passagem a seguir:

P: Qual o papel das espumas no processo de remoção da sujeira? A3, A5 e A22: Nenhuma. A24: Na verdade, se formar muita ou pouca espuma não tem nada a ver com a limpeza,é apenas um atrativo, a diferença é para o meio ambiente e não para o processo de limpeza... já que se formar muita ou pouca espuma, mas formar micela estável, vai limpar de qualquer jeito.

Os alunos A4 e A24 finalizaram a discussão apresentando a sugestão de as empresas fabricantes dos detergentes serem responsáveis por colocar o mínimo possível de substâncias espumantes na fórmula do produto, de modo a evitar maior poluição ao meio ambiente.

Estudo de caso referente a quarta aula da SDI: Os alunos foram para o Laboratório realizar dois testes: Teste $\mathbf{1}$ - Análise visual da concentração dos produtos responsáveis por remover a sujeira em quatro marcas de detergentes neutros; e Teste $\mathbf{2}$ - Comparação da 
viscosidade do detergente e do amaciante comum, utilizando um dispositivo no qual uma pequena esfera atravessava a mesma profundidade de líquidos distintos em tempos diferentes (Figura 2).

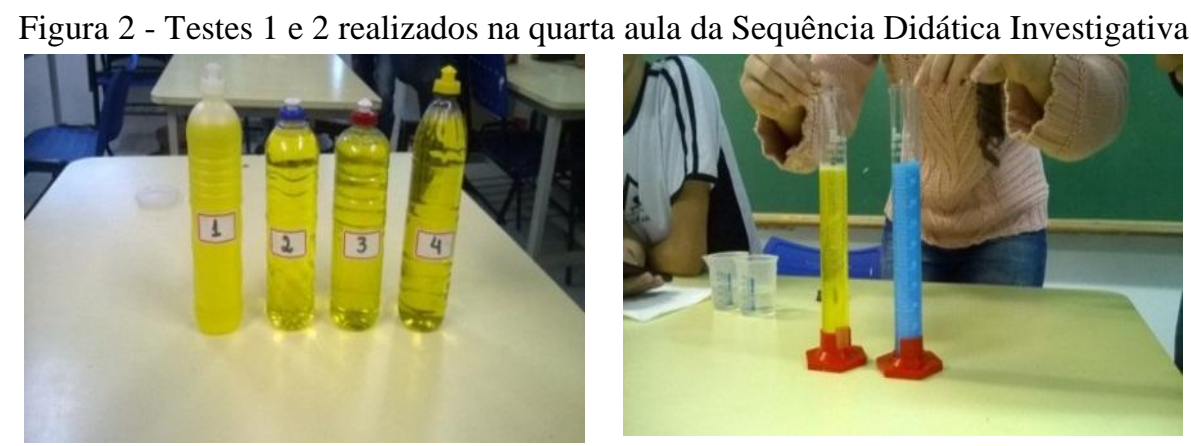

Fonte: Autores.

Para fazer o Teste 1, os grupos receberam quatro amostras de detergentes neutros diferentes, cujos rótulos foram substituídos por etiquetas numeradas de 1 a 4 . Os alunos foram orientados a homogeneizar (agitar) as amostras e observar a sua consistência e coloração. Além disso, a professora disponibilizou aos grupos um pequeno recipiente de plástico transparente para gotejar o detergente e verificar a sua viscosidade. Após realizar o Teste 1, a professora deixou 10 minutos para os alunos fazerem a discussão e anotações das observações acerca do que foi verificado na atividade. Em seguida, explicou o conceito de viscosidade e fez uma pergunta à turma, que fomentou a seguinte discussão:

P: Se o líquido é muito viscoso, ele deve ser mais ou menos concentrado? A turma foi unânime em responder que é mais concentrado. P: Se o detergente está com uma cor mais intensa que outro, o que isso pode indicar? A8, A17 e A21 disseram: Mais concentrado.

A partir da discussão anterior, foram abordados os conceitos de viscosidade e concentração, além das vantagens de se utilizar um amaciante concentrado em relação ao comum, principalmente em termos ambientais. Na sequência, realizou o Teste 2, proposto por Vaz et al. (2012), em que foi cronometrado o tempo gasto para o escoamento de uma pequena esfera de aço no detergente e no amaciante. $\mathrm{O}$ experimento foi feito em triplicata, sendo inicialmente com o amaciante e depois com o detergente. Os tempos cronometrados para o detergente e para o amaciante estão mostrados no Quadro 2 a seguir.

Quadro 2 - Tempos cronometrados para o detergente e para o amaciante comum
\begin{tabular}{|c|c|c|}
\hline $\begin{array}{c}\text { ORDEM PARA OS } \\
\text { TEMPOS }\end{array}$ & AMACIANTE COMUM & DETERGENTE \\
\hline $\mathbf{1}$ & $48 \mathrm{~s}$ & $65 \mathrm{~s}$ \\
\hline
\end{tabular}




\begin{tabular}{|c|c|c|}
\hline $\mathbf{2}$ & $58 \mathrm{~s}$ & $56 \mathrm{~s}$ \\
\hline $\mathbf{3}$ & $38 \mathrm{~s}$ & $87 \mathrm{~s}$ \\
\hline MÉDIA & $48 \mathrm{~s}$ & $69 \mathrm{~s}$ \\
\hline
\end{tabular}

Fonte: Autores.

A média dos tempos cronometrados para o detergente neutro foi superior ao do amaciante comum, concluindo que o detergente se mostrou mais viscoso que o amaciante. No entanto, isso não era o esperado. Sendo assim, a professora debateu com os alunos o resultado obtido, verificando-se o seguinte argumento de A1 para explicar a situação experimental observada: "Devem ter colocado muita água nesse amaciante, ele está menos concentrado... logo, está menos viscoso". A partir dessa passagem, verificamos que o experimento, a princípio demonstrativo, se tornou uma prática investigativa, em que os alunos foram confrontados a proporem uma explicação para o resultado encontrado. Destaca-se ainda que eles puderam relacionar, de maneira direta, o experimento com um dos temas químicos trabalhados na SDI: concentração de soluções. Além disso, as perguntas propostas pela professora no decorrer da atividade e no fechamento da mesma não se restringiram apenas a confirmar o que os estudantes já sabiam a respeito do assunto, mas permitiu a eles pensar, refletir e propor hipóteses na tentativa de respondê-las.

Estudo de caso referente a quinta aula da SDI: Os alunos foram para o Laboratório e, em grupo, resolveram as três primeiras questões da SDI (questões relacionadas à função do sabão no processo de limpeza e ao impacto do descarte do detergente no ambiente). Após a resolução das atividades propostas, os discentes foram para a quadra de esportes da Escola produzir o sabão ecológico. Lá eles tiveram a oportunidade de verificar como o óleo usado em casa pode ser reutilizado para a fabricação do sabão. Os alunos ficaram muito empolgados ao produzirem o sabão ecológico e propuseram a realização do projeto ECObolhas: limpe a sua consciência. Esse projeto assumiu um caráter interdisciplinar, já que foi desenvolvido juntamente com a professora de Biologia ao longo de três meses. Os principais objetivos do Projeto foi incentivar o reaproveitamento do óleo usado em casa para a fabricação de sabão, bem como orientar os alunos e a comunidade escolar sobre o uso correto e consciente dos produtos de limpeza. Esse Projeto foi socializado na Escola em um dos sábados letivos que contou com a presença da comunidade educativa. Os alunos, motivados com a receita do sabão que aprenderam na aula, fizeram algumas modificações na formulação e produziram cinco diferentes tipos de sabões e sabonetes ecológicos/sustentáveis, os quais foram oferecidos como brinde às pessoas que no dia da apresentação respondiam corretamente às perguntas feitas pelos estudantes em relação ao tema abordado no Projeto ECObolhas. 
Estudo de caso referente a sexta aula da SDI: A professora iniciou a aula abordando uma questão de proporcionalidade: Para fabricar o sabão ecológico foi necessário dissolver certa quantidade de soda cáustica em água. Em seguida, foi misturado óleo filtrado a essa solução. Caso fosse necessário triplicar a receita, qual a quantidade de soda cáustica, água e óleo precisaríamos utilizar? A turma foi unânime em responder que deveria triplicar os componentes da receita. A partir dessa discussão inicial, foi feita a revisão de Estequiometria. A professora discutiu algumas estratégias que poderiam auxiliar os alunos na resolução das questões que abordam este conteúdo, com destaque para as relações ponderais que devem ser estabelecidas entre os reagentes e os produtos. Na sequência, sugeriu as seguintes etapas para a resolução: (i) escrever a equação química apresentada no problema; (ii) balancear a equação química, observando que os coeficientes estequiométricos indicam as proporções em quantidade de matéria (mol) existente entre os componentes da reação; (iii) estabelecer uma relação de proporcionalidade (regra de três simples) entre o dado apresentado e a pergunta do problema, que poderá ser escrita em massa, volume ou mols, conforme as conveniências do problema; e (iv) escrever a segunda linha da regra de três utilizando informações contidas no seguinte esquema, obedecendo os coeficientes estequiométricos da equação: 1 mol _ massa atômica ou massa molecular $(\mathrm{g}) \_6 \times 10^{23}$ átomos ou moléculas _ 22,4 L (CNTP). Em seguida, a professora propôs à turma fazer uma atividade que demonstrou a importância do balanceamento das equações químicas. Para isso, A4, A5, A13 e A18 foram convidados a se levantarem, sendo dois deles para representar (personificar) a molécula do $\mathrm{H}_{2}$ e os outros dois a do $\mathrm{Br}_{2}$. Após a simulação utilizando esta analogia para descrever a ocorrência da reação química entre os gases $\mathrm{H}_{2}$ e $\mathrm{Br}_{2}$, os alunos concluíram que foram formados dois mols de $\mathrm{HBr}$, conforme a reação descrita a seguir: $\mathrm{H}_{2}(\mathrm{~g})+\mathrm{Br}_{2}(\mathrm{~g}) \rightarrow 2 \mathrm{HBr}(\mathrm{g})$. Neste momento, a professora teve o cuidado de verificar se a situação havia sido compreendida pelos alunos a partir das relações analógicas estabelecidas. Isso porque é essencial que o professor discuta as limitações inerentes às analogias, de maneira a evitar uma compreensão equivocada das mesmas (MONTEIRO; JUSTI, 2000). A professora aproveitou a atividade para enfatizar o sentido do balanceamento nas equações químicas, explicando que nas transformações os átomos não desaparecem. Eles apenas se rearranjam para formar novos produtos. Por fim, verificamos que esta atividade favoreceu uma melhor compreensão dos aspectos conceituais relacionados à Estequiometria das reações químicas, já que o alto grau de abstração foi minimizado pela dinâmica com a representação concreta/analogia para abordar o assunto. 
Estudo de caso referente a sétima aula da SDI: Nesta aula, os alunos foram para o Laboratório e resolveram, em grupo, duas questões contextualizadas da SDI relativas ao conteúdo de Estequiometria. Elas apresentavam equações químicas que descreviam as reações para produção de dois componentes dos sabões: palmitado de potássio e laureato de sódio. Ao analisarmos as questões entregues pelos cinco grupos ao final da aula, foi possível verificar que todos eles resolveram corretamente o que foi solicitado nos enunciados, relacionando adequadamente as grandezas massa, quantidade de matéria e número de Avogadro. Ou seja, conseguiram estabelecer as proporções corretas por meio das regras de três simples que foram necessárias às resoluções. No entanto, constatamos a necessidade de abordar a Estequiometria conjuntamente com as disciplinas de Português e Matemática, considerando que se verificou dúvidas relacionadas a não compreensão do enunciado em dois grupos, bem como uma expressiva dificuldade para eles estabelecerem as proporções algébricas corretamente. Esta constatação corrobora com os principais obstáculos em Estequiometria discutidos no trabalho de Costa e Souza (2013). As dúvidas que surgiram na aula, entretanto, foram prontamente resolvidas na interação que permeou os grupos, sempre supervisionados e orientados pela professora, que apresentava os devidos esclarecimentos quando estes se faziam necessários.

Estudo de caso referente a oitava aula da SDI: A professora iniciou a aula com uma breve revisão dos conceitos relativos a soluto, solvente, solução, dissolução e diluição. Começou questionando a diferença entre dissolver e diluir. Como os alunos já haviam estudado este conteúdo, eles responderam com facilidade. A8 disse que "dissolver é acrescentar o soluto no solvente e esse soluto se dissolve; já diluir é acrescentar solvente em uma solução já preparada". Na sequência, a professora perguntou o que seria necessário para preparar uma solução, buscando ampliar a discussão. A17 respondeu "soluto e solvente". Após definir o que seria soluto e solvente, a professora perguntou: qual é o solvente universal? Os alunos foram unânimes em responder que era a água.

P: No preparo do sabão ecológico foi feito uma dissolução ou uma diluição? A23:

Dissolução, solução? P: Vocês acham que eu estou falando do quê? A23: Quando colocamos a soda cáustica em água.

Alguns alunos identificaram corretamente o soluto e o solvente na mistura feita para preparar o sabão ecológico, tal como expresso por A23: a soda cáustica (soluto) se dissolve em água (solvente). Na sequência, a professora questionou: quando vocês misturaram a soda cáustica em água, o que vocês estavam fazendo? A21 e A23 responderam que esse processo 
foi uma dissolução e não uma diluição. Em seguida, a professora perguntou o tipo de ligação química presente na soda cáustica. Os alunos responderam em coro que era a Ligação Iônica. Em seguida, a professora explicou que o tipo de interação química presente nos compostos iônicos é a íon-íon e apresentou mais uma pergunta: qual o tipo de ligação química presente na molécula de água? A5 respondeu: É a Ligação Covalente. A professora complementou a resposta de A5 dizendo que a interação química presente entre as moléculas de água seria a Ligação de Hidrogênio. Na sequência, mostrou a diferença entre ligação química e interações químicas. Ao explicar como acontece o processo de dissolução, quando as interações estabelecidas entre soluto-solvente são mais intensas que as soluto-soluto ou solvente-solvente, a professora verificou que naquele momento eles não pensaram na dissolução em termos de interações químicas, confirmando, assim, a expressiva dificuldade em transitar pelos três níveis de compreensão da matéria, sendo eles o macroscópico ou descritivo, o representacional ou simbólico e o submicroscópico ou explicativo (SANTOS, 2013). Por fim, a professora fez mais uma pergunta à turma, motivando a discussão a seguir:

P: Se tivéssemos preparado a solução de soda cáustica e ela tivesse ficado forte demais, $o$ que poderia ser feito? A8, A17 e A23 responderam que fariam uma diluição, ou seja, deveria acrescentar água a essa solução. P: O que acontece com o volume da solução final, ou seja, após a diluição? A3, A5, A8 e A17: Aumenta. P: E a massa de soda cáustica, o número de mols se altera? A3, A5, A8 e A17: Não. P: E a concentração dessa solução, sofre ou não alteração? A turma foi unânime em responder que a solução ficaria menos concentrada.

Com este fechamento, foi possível concluir que houve entendimento sobre a diferença que perpassa os conceitos de dissolver e diluir, além da relação estabelecida na concentração das soluções.

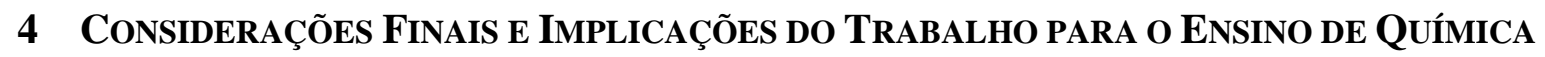

A descrição e análise apresentadas neste trabalho nos permitiu constatar que a SDI trabalhada nas aulas contribuiu para que os alunos vivenciassem práticas formativas autênticas, contextuais e relacionadas ao fazer Ciência. Verificamos também que a abordagem de temas CTS despertou um maior interesse pelo conteúdo da Química e, diferentemente do que ocorreu nas aulas tradicionais, possibilitou um ensino mais dialógico. Isso permitiu à professora 
fomentar discussões que favoreceram o desenvolvimento de atitudes mais responsáveis e sustentáveis.

Verificou-se, ainda, que a simulação/analogia proposta para discutir o balanceamento de reações químicas, bem como a montagem do modelo para representar uma micela, permitiram engajar os alunos na dinâmica de ensino, criando um ambiente descontraído e propício ao aprendizado. Além disso, a análise dos dados demonstrou que ao abordar o conteúdo de Cálculos Estequiométricos por meio de atividades experimentais investigativas, com questões sociocientíficas permeando as discussões, foi possível problematizar o conteúdo e favorecer uma formação mais crítica sobre o conhecimento científico discutido em sala de aula. Isso favoreceu um ensino dinâmico e participativo, possibilitando aos alunos uma melhor compreensão do conteúdo de cálculos químicos, bem como uma formação cidadã por meio de leituras diferenciadas sobre a relação sujeito / ambiente / conhecimento científico.

Por fim, a SDI discutindo "Sabões e Detergentes" fomentou possibilidades de estudos futuros relacionados à Argumentação no ensino de Ciências e as Interações Discursivas em sala de aula. No entanto, essas temáticas não foram tratadas com o devido aprofundamento neste artigo, pois não faziam parte do nosso objeto de investigação inicial. Mas reconhecemos a importância de serem abordadas em pesquisas futuras, possibilitando diálogos com as seguintes áreas: Abordagem CTS no Ensino de Ciências; Linguagens, Representações e Gestos no Ensino de Ciências; e o Ensino de Ciências por Investigação. Acreditamos que tais perspectivas de pesquisas têm o potencial para favorecerem boas discussões na Educação em Ciências, que poderão ter impactos diretamente nos processos e práticas de formação inicial e continuada dos professores, trazendo contribuições relevantes para esta área de estudos.

\section{REFERÊNCIAS}

BRASIL. Base Nacional Comum Curricular: Ensino Médio. Brasília: MEC/Secretaria de Educação Básica, 2018. Disponível em: http://basenacionalcomum.mec.gov.br/. Acesso em: 01 jun. 2019.

CARVALHO, Anna Maria Pessoa de. Ensino e aprendizagem de Ciências: referenciais teóricos e dados empíricos das sequências de ensino investigativas (SEI). In: LONGHINI, Marcos Daniel (Org.). O uno e o diverso na educação. Uberlândia: EDUFU, 2011, p. 253 266.

CARVALHO, Anna Maria Pessoa de. O ensino de ciências e a proposição de sequências de ensino investigativas. In: CARVALHO, Anna Maria Pessoa de (Org.). Ensino de Ciências por Investigação: condições para implementação em sala de aula. São Paulo: Cengage Learning, 2013, p. 1-20. 
CARVALHO, Anna Maria Pessoa de. Fundamentos Teóricos e Metodológicos do Ensino por Investigação. Revista Brasileira de Pesquisa em Educação em Ciências, v. 18, n. 3, p. 765 794, 2018. Disponível em: https://periodicos.ufmg.br/index.php/rbpec/article/view/4852. Acesso em: 04 jun. 2019.

COSTA, Ana Alice Farias da; SOUZA, Jorge Raimundo da Trindade. Obstáculos no processo de ensino e de aprendizagem de cálculo estequiométrico. Amazônia: Revista de Educação em Ciências e Matemática, v.10, n. 19, p. 106-116, ago./dez. 2013. Disponível em: https://periodicos.ufpa.br/index.php/revistaamazonia/article/view/2190. Acesso em: 14 nov. 2018.

FERRAZ, Arthur Tadeu; SASSERON, Lúcia Helena. Espaço Interativo de Argumentação Colaborativa: Condições criadas pelo professor para promover argumentação em aulas investigativas. Revista Ensaio, v. 19, p. 1-25, 2017. Disponível em: https://www.scielo.br/scielo.php?script=sci_arttext\&pid=S198321172017000100215\&lng=pt\&nrm=iso. Acesso em: 12 nov. 2018.

FREIRE, Paulo. Pedagogia do oprimido. 17ª ed. Rio de Janeiro: Paz e Terra, 1987.

GARCIA, Irene Teresinha Santos; KRUGER, Verno. Implantação das Diretrizes Curriculares Nacionais para Formação de Professores de Química em uma Instituição Federal de Ensino Superior: Desafios e perspectivas. Química nova, v. 32, n. 8, p. 2218-2224, 2009. Disponível em: https://www.scielo.br/scielo.php?pid=S010040422009000800039\&script=sci_abstract\&tlng=pt. Acesso em: 05 jul. 2018.

GODOY, Arilda Schmidt. Pesquisa Qualitativa: Tipos fundamentais. Revista de Administração de Empresas. v. 35, n. 3, p. 20-29, mai/Jun, 1995. Disponível em: https://www.scielo.br/scielo.php?script=sci_arttext\&pid=S0034-75901995000300004. Acesso em: 03 fev. 2019.

GUIMARÃES, Cleidson Carneiro. Experimentação no Ensino de Química: Caminhos e Descaminhos Rumo à Aprendizagem Significativa. Química Nova na Escola, v. 31, n. 3, p. 198-202, ago. 2009. Disponível em: http://qnesc.sbq.org.br/online/qnesc31_3. Acesso em: 03 fev. 2019.

JOHNSTONE, Alex H. The development of chemistry teaching: a changing response to changing demand. Journal of Chemical Education, Washington, v. 70, n. 9, p. 701-705, 1993. Disponível em: https://pubs.acs.org/doi/abs/10.1021/ed070p701. Acesso em: 03 fev. 2019.

LATINI, Rose Mary; SANTOS, Maria Bernadete Pinto dos; CANESIN, Fátima de Paiva; COTELO, Patrícia Fernanda da Silva Moraes. A Abordagem Ciência- Tecnologia-Sociedade no Ensino de Química. Revista Práxis. Ano V, n. 10, p. 11-19, dez, 2013. Disponível em: http://revistas.unifoa.edu.br/index.php/praxis/article/view/614. Acesso em: 26 ago. 2018.

LEAL, Cristianni Antunes; FONSECA, Gisele Rôças de Souza. Vamos brincar de quê?: Os jogos cooperativos no ensino de Ciências. 2013. 166 f. Dissertação (Mestrado Profissional em Ensino de Ciências) - Instituto Federal de Educação, Ciência e Tecnologia do Rio de Janeiro, Rio de Janeiro, RJ, 2013. 
LOURENÇO, Ilza Mara Barros; MARCONDES, Maria Eunice Ribeiro. Um plano de ensino para mol. Química nova na escola, n. 18, p. 22-25, nov. 2003. Disponível em: http://qnesc.sbq.org.br/online/qnesc18/A05.PDF. Acesso em: 26 ago. 2018.

MÉKSENAS, Paulo. Aspectos metodológicos da pesquisa empírica: a contribuição de Paulo Freire. Revista Espaço Acadêmico, Maringá (PR), ano VII, n.78, nov, 2007. Disponível em: http://www.espacoacademico.com.br/078/78. Acesso em: 20 nov. 2018.

MONTEIRO, Ivone Garcia; JUSTI, Rosária da Silva. Analogias em livros didáticos de química brasileiros destinados ao ensino médio. Investigações em Ensino de Ciências, v. 5, n. 2, p. 67-91, 2000. Disponível em:

http://www.if.ufrgs.br/ienci/ienci_old.php?go=artigos\&idEdicao=17\#. Acesso em: 20 fev. 2019.

PIO, Jucélia Marize. Visão de alunos do ensino médio sobre dificuldades na aprendizagem de cálculos estequiométricos. 2006. 33 f. Monografia (Licenciatura em Química) - Faculdade de Educação da Universidade Federal de Minas Gerais, Belo Horizonte, MG, 2006.

POZO, Juan Ignacio; CRESPO, Miguel Ángel Gómez. A aprendizagem e o Ensino de Ciências: do conhecimento cotidiano ao conhecimento científico. $5^{\text {a }}$. ed. Porto Alegre (RS): Artmed, 2009.

SANTANA, Ronaldo Santos; CAPECCHI, Maria Cândida Varone de Morais; FRANZOLIN, Fernanda. O ensino de ciências por investigação nos anos iniciais: possibilidades na implementação de atividades investigativas. Revista Electrónica de Enseñanza de las Ciencias, v. 17, n. 3, p. 686-710, 2018. Disponível em:

http://reec.uvigo.es/volumenes/volumen17/REEC_17_3_9_ex1245.pdf. Acesso em: 06 mar. 2019.

SANTOS, Wildson Luiz Pereira dos; SCHNETZLER, Roseli Pacheco. Educação em Química: Compromisso com a cidadania. 4ª ed. Ijuí (RS): Ed. Unijuí, 2010.

SANTOS, Wildson Luiz Pereira dos; MALDANER, Otávio Aloísio. Ensino de química em foco. $1^{\text {a }}$. ed. Ijuí (RS): Ed. Unijuí, 2011.

SANTOS, Lívia Cristina dos. Dificuldades de aprendizagem em Estequiometria: uma proposta de ensino apoiada na modelagem. 2013. 153 f. Dissertação (Pós-graduação em Ensino de Ciências Naturais e Matemática) - Universidade Federal do Rio Grande do Norte, Natal, RN, 2013. Disponível em: https://repositorio.ufrn.br/jspui/handle/123456789/16103. Acesso em: 06 mar. 2019.

SANTOS, Lívia Cristina dos; SILVA, Márcia Gorette Lima da. Conhecendo as dificuldades de aprendizagem no Ensino Superior para o conceito de Estequiometria. Revista de Ensino de Ciências e Matemática Acta Scientiae, Canoas, RS, v. 16, n. 1, p. 133-152, Jan/Abr, 2014. Disponível em: http://www.periodicos.ulbra.br/index.php/acta/article/view/632. Acesso em: 16 jun. 2019.

SASSERON, Lúcia Helena. A alfabetização científica, Ensino por investigação e Argumentação: Relações entre ciências da natureza e escola. Revista Ensaio, v. 17, n. 
especial, p. 49-67, nov. 2015. Disponível em: https://www.scielo.br/pdf/epec/v17nspe/19832117-epec-17-0s-00049.pdf. Acesso em: 16 jun. 2019.

SEDANO, Luciana; CARVALHO, Anna Maria Pessoa de. Ensino de Ciências por Investigação: Oportunidades de Interação Social e sua importância para a Construção da Autonomia Moral. Alexandria, v. 10, n. 1, p. 199-220. 2017. Disponível em: https://periodicos.ufsc.br/index.php/alexandria/article/view/1982-5153.2017v10n1p199. Acesso em: 16 jun. 2019.

SILVA, Schana Andréia da. Elaboração e avaliação de material didático para apoio no ensino de cálculo estequiométrico em um curso técnico de química. 2015. 86 f. Trabalho de Conclusão de Curso (Licenciatura em Química) - Universidade Federal do Rio Grande do Sul, Porto Alegre, RS, 2015. Disponível em: https://www.lume.ufrgs.br/bitstream/handle/10183/139087/000987656.pdf?sequence=1. Acesso em: 15 jun. 2019.

VAZ, Ednilson Luiz Silva; ACCIARI, Heloisa Andréa; ASSIS, Alice; CODARO, Eduardo Norberto. Uma experiência didática sobre viscosidade e densidade. Química Nova na Escola, v. 34, n.3, p. 155-158, Agosto, 2012. Disponível em: http://qnesc.sbq.org.br/online/qnesc34_3/08-EEQ-111-10.pdf. Acesso em: 13 ago. 2018.

YIN, Robert K. Estudo de Caso: Planejamento e métodos. $3^{\text {a }}$. ed. Porto Alegre: Bookman, 2005.

ZÔMPERO, Andreia Freitas; LABURÚ, Carlos Eduardo. Atividades Investigativas no Ensino de Ciências: Aspectos históricos e diferentes abordagens. Ensaio, v. 13, n. 3, p. 67-80. 2011. Disponível em: https://www.scielo.br/pdf/epec/v13n3/1983-2117-epec-13-03-00067.pdf. Acesso em: 13 ago. 2018.

Recebido em: 31 de maio de 2020.

Aprovado em: 24 de agosto de 2020. 